\title{
Gas-liquid two-phase flow behaviors and performance characteristics of proton exchange membrane fuel cells in a short-term microgravity environment
}

\author{
Hang Guo a, c, *, Xuan Liu ${ }^{\text {a, }}$ Jian Fu Zhao ${ }^{\text {b, d }}$, Fang Ye ${ }^{a}$, Chong Fang Ma ${ }^{a}$ \\ ${ }^{a}$ MOE Key Laboratory of Enhanced Heat Transfer and Energy Conservation, Beijing Key Laboratory of Heat Transfer and Energy Conversion, College of \\ Environmental and Energy Engineering, Beijing University of Technology, Beijing, 100124, China \\ ${ }^{\mathrm{b}}$ Key Laboratory of Microgravity, Institute of Mechanics, Chinese Academy of Sciences, Beijing, 100190, China \\ ${ }^{\mathrm{c}}$ Collaborative Innovation Center of Electric Vehicles in Beijing, Beijing, 100081, China \\ d School of Engineering Science, University of Chinese Academy of Sciences, Beijing, 100049, China
}

\section{H I G H L I G H T S}

- Microgravity experiments are operated at lower temperature.

- Channel orientations affect the performance of PEMFCs in a microgravity environment.

- Water in vertical channels is easily expelled in microgravity environment.

- Gravity slightly affects the two-phase flow behaviors of PEMFCs with horizontal channels.

\section{A R T I C L E I N F O}

\section{Article history:}

Received 22 January 2017

Received in revised form

26 March 2017

Accepted 28 March 2017

Available online 5 April 2017

\section{Keywords:}

Proton exchange membrane fuel cell

Microgravity

Performance

Two-phase flow

Visual observation

\begin{abstract}
A B S T R A C T
In this work, proton exchange membrane fuel cells (PEMFCs) with transparent windows are designed to study the gas-liquid two-phase flow behaviors inside flow channels and the performance of a PEMFC with vertical channels and a PEMFC with horizontal channels in a normal gravity environment and a $3.6 \mathrm{~s}$ short-term microgravity environment. Experiments are conducted under high external circuit load and low external circuit load at low temperature where is $35^{\circ} \mathrm{C}$. The results of the present experimental work demonstrate that the performance and the gas-liquid two-phase flow behaviors of the PEMFC with vertical channels exhibits obvious changes when the PEMFCs enter the $3.6 \mathrm{~s}$ short-term microgravity environment from the normal gravity environment. Meanwhile, the performance of the PEMFC with vertical channels increases after the PEMFC enters the $3.6 \mathrm{~s}$ short-term microgravity environment under high external circuit load, while under low external circuit load, the PEMFC with horizontal channels exhibits better performance in both the normal gravity environment and the $3.6 \mathrm{~s}$ short-term microgravity environment.
\end{abstract}

(c) 2017 Elsevier B.V. All rights reserved.

\section{Introduction}

PEMFCs, which exhibit high energy conversion efficiency, low operating temperature, clean emission, and circularity, can be widely utilized in aerospace, military, and air independent

\footnotetext{
* Corresponding author. MOE Key Laboratory of Enhanced Heat Transfer and Energy Conservation, Beijing Key Laboratory of Heat Transfer and Energy Conversion, College of Environmental and Energy Engineering, Beijing University of Technology, Beijing, 100124, China.

E-mail address: hangguo@sohu.com (H. Guo).
}

propulsion (AIP) diving equipment, etc. Fuel cell technology was first utilized in GEMINI spacecraft by the National Aeronautics and Space Administration (NASA) [1], and an alkaline fuel cell (AFC) system was successfully utilized in the APOLLO mission in 1960s. A novel AFC system with an asbestos membrane (PC17-C) was developed by the United Technology Corporation, and an electricity generator equipped with a PC17-C AFC system was successfully utilized in a spacecraft in 1981. By the late 1980s, researchers realized that AFCs were easily contaminated by carbon dioxide, and asbestos were pernicious to health. Studies on AFCs were shifted to PEMFCs, which exhibited higher efficiency, lower cost, and longer 
life span; thus, AFCs had almost been replaced by PEMFCs [2,3]. PEMFCs system in space crafts worked as electricity generators and reactant generating devices, which were called regenerative fuel cell (RFC) [4].

Water management, which determines the characteristics of gas-liquid two-phase flow and mass distribution, significantly affects the output performance of PEMFCs [5-7]. Liu et al. [8] critically reviewed the studies related to interfacial phenomena and heat management, which showed close relationships with water and heat management; meanwhile, interfacial phenomena effects on water and heat behaviors in a PEMFC were discussed further, which made great contributions to the study of water and heat management in PEMFCs. To experimentally study the two-phase flow behaviors and obtain the images, many approaches had been adopted including the X-ray radiographic method, neutron radiography method, fluorescence microscopy method and installing a transparent window on the end plate. Many researchers [9-13] studied the water transportation and accumulation inside the chamber using neutron radiography method and fluorescence microscopy method. Meanwhile, many researchers [14-16] studied the liquid water transportation and accumulation behaviors in the inner space of a PEMFC using X-ray radiographic method. The method mentioned above, including the neutron radiography method, fluorescence microscopy method and X-ray radiographic method, were of high cost and needed high space occupation and could not directly supply the images of gas-liquid two-phase flow behaviors [17]. Some researchers [18-20] developed PEMFCs with transparent windows to capture images of the gas-liquid twophase flow of the inner chamber of PEMFCs. Chen et al. [21] investigated the air-water two-phase flow behaviors in parallel channels of a PEMFC with a self-designed transparent cathode plate, and they observed that channels filled by porous media could optimize water management in PEMFCs. Weng et al. [22,23] experimentally investigated the water flooding in the cathode of a PEMFC with a transparent end plate, and they discovered that operating conditions (e.g., cell temperature and gas flow rate) significantly affected the water flooding behaviors and performance of a PEMFC. Tüber et al. [24] studied two-phase flow and transportation behaviors in the cathode of a transparent serpentine PEMFC, and they found that air stoichiometry, temperature, air humidity, and other parameters affect water transportation behaviors. Spernjak et al. [25] experimentally investigated the liquid water formation and transportation behaviors in a PEMFC with a transparent single-serpentine flow field, and they observed that a high amount of water in channels indicated more effective removal of water from the catalyst layer. Hu et al. [26] designed 3 single PEMFCs with transparent end plates and compared their performance, the results showed that the performance of a conventional fuel cell was better than the performance of a fuel cell with transparent end plates.

The studies mentioned above were conducted experimentally to investigate the effects of flow field structures and membrane electrode assembly (MEA) properties on gas-liquid two-phase flow and performance of PEMFCs, whereas the effect of gravity on gasliquid two-phase flow and performance were investigated as well. Najjari et al. [27] developed a one-dimensional (1-D) and transient model to investigate the effects of gravity on water accumulating at the interface between catalyst layer and gas diffusion layer in a PEMFC. They observed that gravity had significant effects on the transient time and voltage under stable conditions. Chen et al. [28] experimentally studied the effects of cathodeupward position and anode-upward position on water removal in the cathode of a PEMFC at different operating conditions, and they remarked that the anode-upward position was advantageous in removing water from the cathode, which led to greater performance of PEMFC. Nishida et al. [29] investigated water blockage in the cathode flow field using in-situ visualization method, and the results showed that liquid water was easily removed from horizontal channels. Lee et al. [30] experimentally studied the channel orientation effects on the polarization curves of PEMFCs with serpentine flow channels, which showed that different channel orientations affected the performance of PEMFCs under the effects of gravity on water removal.

Due to the obvious effects of gravity level on two-phase flow and performance in PEM-based fuel cells, the authors [31-35] of the present work did a series of studies on two-phase flow behaviors and performance of direct methanol fuel cells in microgravity as well. Few studies on fuel cells in microgravity have been reported, whereas some researchers focused on the study of two-phase flow in microgravity. Li et al. [36] presented a theoretical model to study the surface force effects on droplet expelling in microgravity, and simulation results showed that an external force was required to move the droplet on the solid surface. Zhao et al. [37-40] presented a semi-theoretical Weber number model to predict the flow transition and gas-liquid two-phase flow in microgravity, and results of this work became a powerful aid for the further investigation of two-phase flow in microgravity; meanwhile, experiments were conducted on two-phase flow pattern in microgravity as well. Narcy et al. [41] experimentally studied the forced convection boiling behaviors of HFE-7000 in normal gravity and microgravity, and they also analyzed the flow pattern and heat transfer behaviors inside the flow channels. Konishi et al. [42,43] studied the flow boiling behaviors of FC-72 in microgravity and analyzed the effects of different operating condition on the flow boiling behaviors under different gravity conditions. Jong et al. [44] investigated the twophase annular flow under different flow behaviors in microgravity using the film thickness time trace measurements.

Space power equipment is one of the most promising application areas for PEMFCs. Gas-liquid two-phase flow behaviors significantly affect the performance of a PEMFC. Because of the specificity of the experimental environment of microgravity, several previous researchers conducted experiments in microgravity to investigate the gas-liquid two-phase flow behaviors and performance of PEMFCs at $65^{\circ} \mathrm{C}$ high temperature [35]. PEMFCs working at $65{ }^{\circ} \mathrm{C}$ needs heating devices and energy consumption and therefore PEMFCs working at lower temperature are more suitable for the application in space power equipment. In the present experimental work, a PEMFC with vertical channels and a PEMFC with horizontal channels are designed to investigate the performance changes and the gas-liquid two-phase flow characteristics under different external circuit loads at a normal gravity environment and a $3.6 \mathrm{~s}$ short-term microgravity environment at a lower temperature where is $35^{\circ} \mathrm{C}$. To make the testing system light and simple, PEMFCs with transparent windows are designed to capture the images of two-phase flow behaviors instead of using other complicated method like neutron radiography method, fluorescence microscopy and X-ray radiography method etc. Performance curves and images of gas-liquid two-phase flow behaviors are obtained to investigate the performance and gas-liquid two-phase flow behaviors of a PEMFC with vertical channels and a PEMFC with horizontal channels under high external circuit load and low external circuit load in a normal gravity environment and a 3.6 s short-term microgravity environment.

\section{Experimental}

\subsection{Microgravity supplying}

A 3.6 s short-time microgravity environment was supplied by a drop capsule in a drop tower (shown in Fig. 1), which was supplied 


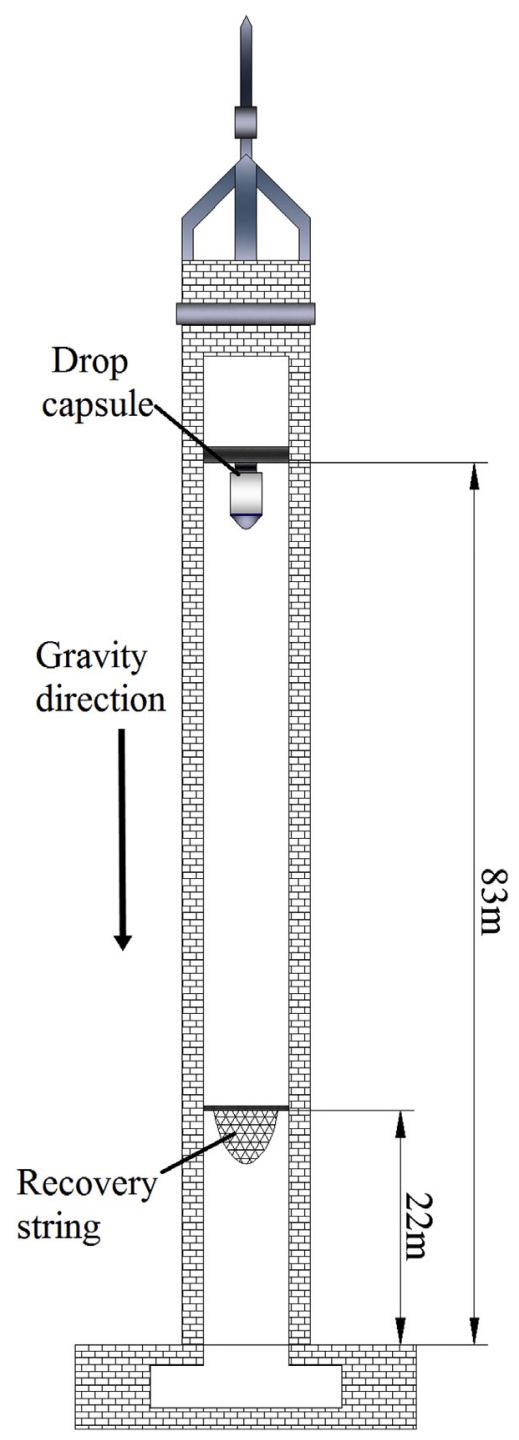

Fig. 1. Microgravity supplying.

by the National-Microgravity Laboratory, Institute of Mechanics, Chinese Academic of Science (CAS). The drop capsule in which the fuel cell component and testing system were installed was freely dropped from the top of the $83 \mathrm{~m}$ high drop tower, and a $3.6 \mathrm{~s}, 10^{-2}$ to $10^{-3} \mathrm{~g}$ microgravity environment was obtained. The drop capsule was recovered by a recovery string bag after the free falling period that a $3.6 \mathrm{~s}$ short-term microgravity environment could be obtained. The testing system was installed in the completely closed drop capsule and operators could not operate the testing system directly. The PEMFC had been running in a steady condition for 90-120 min before it was dropped.

\subsection{Testing system}

A testing system in which PEMFC components and testing system devices were installed was constructed in the present work (shown in Fig. 2). The entire testing system contained gas tanks, gas pressure-reducing valves, gas filters, gas regulators, one-way gas valves, external circuit load and PEMFCs, electromagnetic gas valves, external circuit loads, a high speed video camera, temperature controllers, $\mathrm{I} / \mathrm{O}$ interfaces, and auxiliary components.

\subsection{Fuel cell components}

To investigate the gas-liquid two-phase flow behaviors in cathode flow channels, PEMFCs with transparent windows were designed in this experimental work (shown in Fig. 3). A transparent end plate was utilized at the cathode side of a single cell to obtain the images of gas-liquid two-phase flow behaviors in channels. The PEMFC was constructed by a MEA, flow field plates in anode and cathode, anode end plate, a transparent end plate in cathode and a cathode clamp plate. The MEA, which contained a proton exchange membrane (Nafion112), catalyst layers in anode and cathode, gas diffusion layers (GDL) in anode and cathode, was supplied by BCS Fuel Cells Inc. The active area of the present MEA was $25 \mathrm{~cm}^{2}$ and catalyst load was $1 \mathrm{mg} \mathrm{cm}$. The information of the fuel cell component were listed in Table 1. The reactant gas supplied to the anode was non-humidified hydrogen, while the reactant gas supplied to the cathode was non-humidified oxygen.

\subsubsection{Anode flow field components}

The anode end plate was made of aluminum alloy, which was of low-weight, good mechanical processing, good oxidation resistance and good thermal conductivity. Therefore, the present anode end plate made of aluminum alloy in this work could reduce the total weight of the testing system, which could be utilized in the present drop tower experiments.

The anode flow field plate was made of graphite, which could barrier gas, collect current, conduct heat and resist corrosion. A serpentine flow field structure was used in this experimental work and the dimensional parameters of the serpentine flow field included the channel width, channel depth, and rib width, which all measured $2 \mathrm{~mm}$.

\subsubsection{Cathode flow field components}

To observe the gas-liquid two-phase flow behaviors in the inner place of the cathode flow channels, a transparent end plate made of polycarbonate was used in this experimental work. This kind of transparent end plate design probably decreased the performance of a fuel cell [45]. The light transmittance of the transparent cathode end plate in this work was $90 \%$ and the polycarbonate material was of good mechanical processing and good mechanical strength. To avoid bending of the polycarbonate plate edge, which lead to bad hermetic seal, a cathode clamp plate with a window was constructed on the outside of the transparent cathode end plate.

The material of the cathode flow field plate was the same with that of the anode flow field plate and the flow field structure was processed in the form of serpentine structure. The dimensional parameters of the cathode flow field were as well same with the anode flow field.

\subsection{Data collection}

Data obtained for the present working fuel cell in the normal gravity environment and the $3.6 \mathrm{~s}$ short-term microgravity environment were collected using a multifunctional data collector (AQU1616B) with 8 analogue voltage input channels. Reactant gas flow rate, cell temperature, gravity signal, current density, and voltage were collected using this device. The start-up time of the data collector was $10 \mathrm{~s}$ before the dropping of the capsule and the data collector was turned off after $100 \mathrm{~s}$.

\subsection{High speed camera}

To capture the images of the gas-liquid two-phase flow behaviors, which had quick change and transfer of the gas-liquid twophase flow interface, a high speed camera (VITcam CTC; AOS 


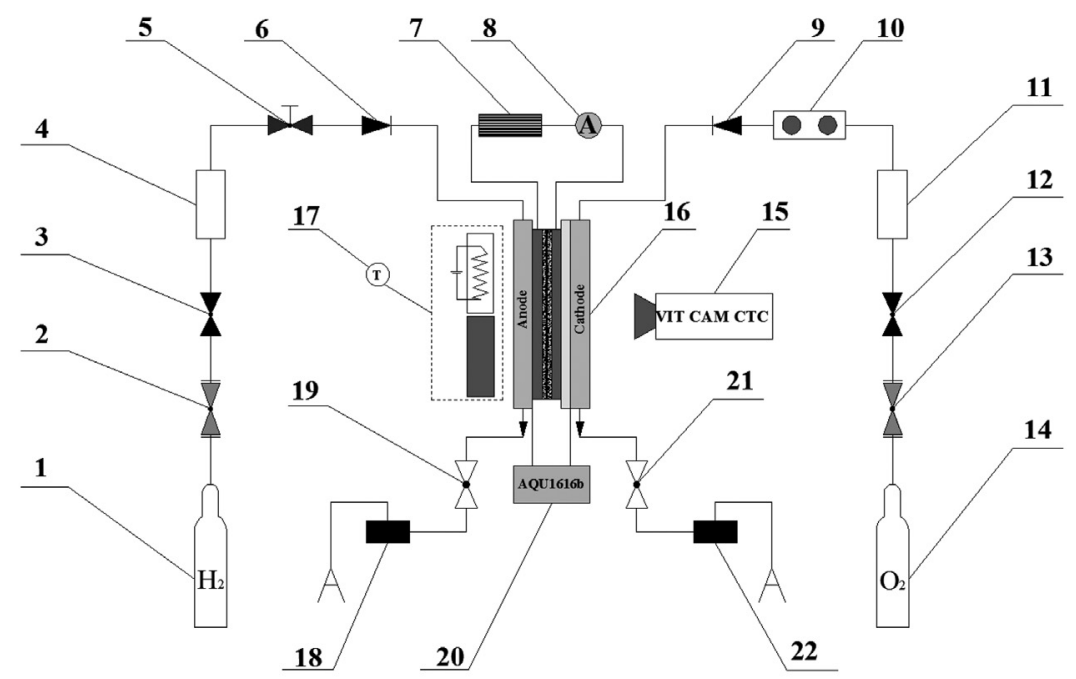

1-Hydrogen tank; 2,13-Gas pressure-drop tanks; 3,12-Solenoid valves; 4,11-Gas filters; 5-Gas flow regulator; 6,9-One-way gas valves; 7-External circuit load; 8-DC sensor; 14-Oxygen tank; 15-High speed video camera; 16-Transparent PEMFC; 17-Tempratrue controllers; 18,22-Liquid water collectors; 19,21-Ball valve; 20-Data collector

(a) Schematics of experimental set-up;

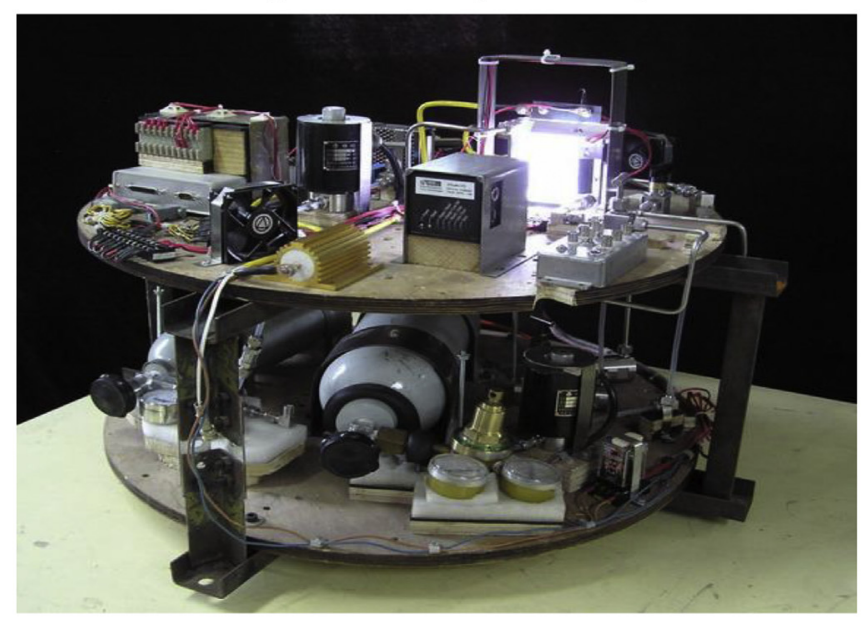

(b) Testing system

Fig. 2. Experimental set up.

Technologies AG, Switzerland) was utilized in this experimental work, which was suitable for the microgravity experiments operated in a drop tower. The high speed camera in this work had a resolution of $1280 \times 1024$ and 8 GB cache space. The maximum shooting speed of this high speed camera was 32000 frame $\mathrm{s}^{-1}$. To record the gas-liquid two-phase flow behaviors in the channels of the PEMFCs, we selected the shutter speed of $1 / 1000 \mathrm{~s}$ and the recording speed of 1000 frames $s^{-1}$ to capture the images of the gas-liquid two-phase flow behaviors in the flow channels. In the meantime, a group of light-emitting diodes were used to lighting the channels, which could make the captured images clear.

\section{Results and discussion}

\subsection{Operating conditions and polarization curve}

Polarization curves of the PEMFCs in the present work are shown in Fig. 4, where X-axis stands for the current density, and Yaxis represents the voltage. $\mathrm{H}_{2}$ flow rate was $180 \mathrm{ml} \mathrm{min}^{-1}$, and $\mathrm{O}_{2}$ flow rate was $60 \mathrm{ml} \mathrm{min}^{-1}$, respectively. The present PEMFCs were operated at $35^{\circ} \mathrm{C}$, where the PEMFC could be started up quickly and no heating devices were needed [46]. The present experimental work was conducted under $\mathrm{R}_{1}=0.03 \Omega$ and $\mathrm{R}_{2}=0.01 \Omega$. The purity of the hydrogen and the oxygen used in this experimental work are both $99.999 \%$. Curves in Fig. 4 shows the data experimentally obtained half a month before the hollow points and the solid points were tested and the points fit the curves well, which means that the experimental data obtained in this work shows a good repeatability. Fig. 4 also shows the polarization curves of the PEMFC with horizontal channels and the PEMFC with vertical channels, which reveals that in the normal gravity environment, the PEMFC with horizontal channels exhibited higher current density compared with the PEMFC with vertical channels under the low external circuit load $\left(R_{2}\right)$. What accounts for this is that: in the normal gravity environment, the liquid water accumulates at the bottom of the vertical channels, while the liquid water can be swept away with the flowing gas in the horizontal channels and the liquid water is not accumulated in the horizontal channels. The concentration polarization of the PEMFC with horizontal channels is lower compared with the PEMFC with vertical channels. Therefore, in the 


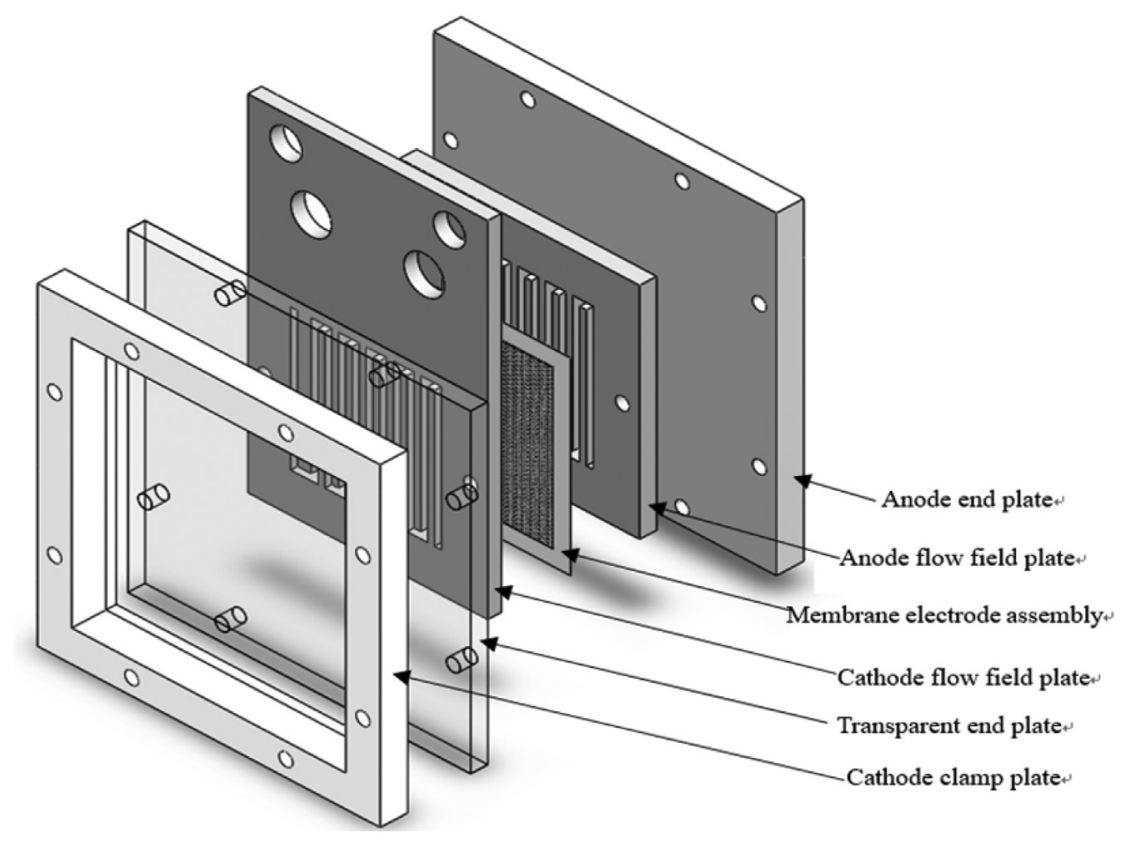

Fig. 3. The PEMFC with a transparent window.

Table 1

Information of the fuel cell components.

\begin{tabular}{|c|c|c|c|}
\hline Item & Data & Item & Material \\
\hline Active area & $25 \mathrm{~cm}^{-2}$ & Membrane & Nafion 112 \\
\hline Pt load & $1 \mathrm{mg} \mathrm{cm}^{-2}$ & Anode end plate & $\begin{array}{l}\text { Aluminum } \\
\text { alloy }\end{array}$ \\
\hline $\begin{array}{l}\text { Anode flow channel } \\
\text { number }\end{array}$ & 11 & Anode flow filed plate & Graphite \\
\hline Anode flow channel depth & $2 \mathrm{~mm}$ & Cathode clamp plate & $\begin{array}{l}\text { Aluminum } \\
\text { alloy }\end{array}$ \\
\hline Anode flow channels width & $2 \mathrm{~mm}$ & $\begin{array}{l}\text { Cathode flow filed } \\
\text { plate }\end{array}$ & Graphite \\
\hline Flow channel number & 11 & Transparent end plate & Polycarbonate \\
\hline $\begin{array}{l}\text { Cathode flow channel } \\
\text { depth }\end{array}$ & $2 \mathrm{~mm}$ & & \\
\hline $\begin{array}{l}\text { Cathode flow channel } \\
\text { width }\end{array}$ & $2 \mathrm{~mm}$ & & \\
\hline
\end{tabular}

normal gravity environment, the PEMFC with horizontal channels exhibits better performance compared with the PEMFC with vertical channels.

\subsection{High external circuit load operating regime}

Fig. 5 shows the performance of the PEMFC with vertical channels and the PEMFC with horizontal channels in the normal gravity environment and the $3.600 \mathrm{~s}$ short-term microgravity environment under high external circuit load $\left(R=R_{1}\right)$, where the operating conditions were: $\mathrm{H}_{2}=180 \mathrm{ml} \mathrm{min}^{-1}, \mathrm{O}_{2}=60 \mathrm{ml} \mathrm{min}^{-1}$, $\mathrm{T}_{\text {cell }}=35^{\circ} \mathrm{C}$. Fig. $5(\mathrm{a})$ and (b) show the performance changes of the present PEMFCs with the gravity change, where $\mathrm{X}$-axis stands for the testing time and Y-axis stands for the voltage (left side) and the current density (right side) respectively. While Fig. 5(c) shows the performance comparison between the PEMFC with vertical channels and the PEMFC with horizontal channels in the normal gravity environment and the $3.6 \mathrm{~s}$ short-term microgravity environment, while X-axis as well stands for the testing time and Y-axis stands for the voltage (left side), the power density (right side) and the current density (right side). The PEMFC enters the $3.6 \mathrm{~s}$ short-term microgravity environment at $0.000 \mathrm{~s}$, whereas the PEMFCs are operated in the normal gravity environment before $0.000 \mathrm{~s}$. The short-term microgravity environment lasts $3.6 \mathrm{~s}$ and afterward, obvious fluctuation can be observed from the gravity signal curves, which means that the PEMFC enters an environment of alternating high gravity and microgravity (shown in Fig. 5(a) and (b)).

Curves in Fig. 5 show that the current density and the power density of the PEMFC with vertical channels are lower compared with those of the PEMFC with horizontal channels in the normal gravity environment, whereas the current density and the power density of the PEMFC with vertical channels are higher than those of the PEMFC with horizontal channels in the $3.6 \mathrm{~s}$ short-term microgravity environment. Therefore, under high external circuit load, the PEMFC with vertical channels exhibits better performance compared with the PEMFC with horizontal channels in the shortterm microgravity environment that lasts $3.6 \mathrm{~s}$, while the PEMFC with horizontal channels exhibits better performance compared

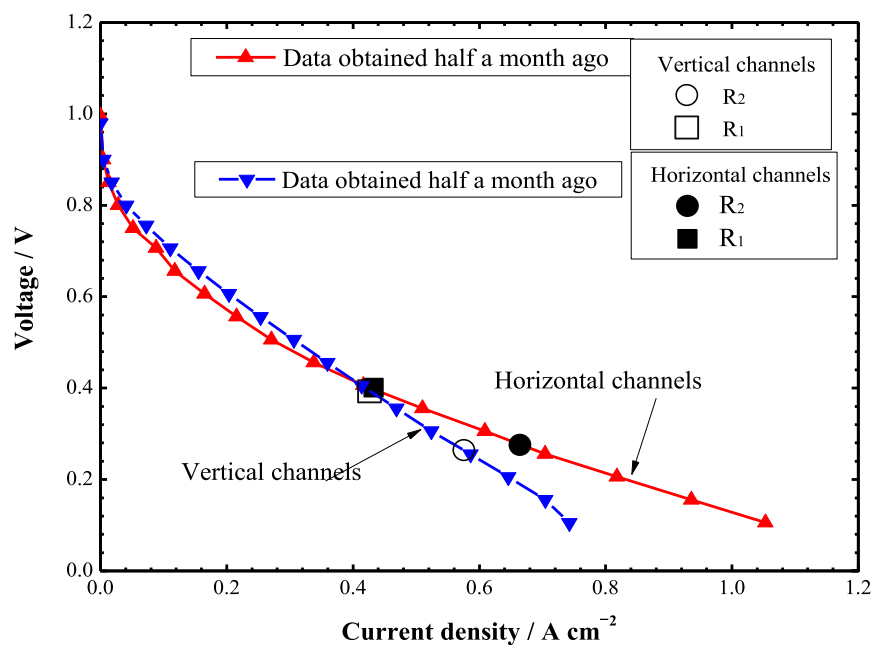

Fig. 4. Polarization cures of PEMFCs in the normal gravity environment. 


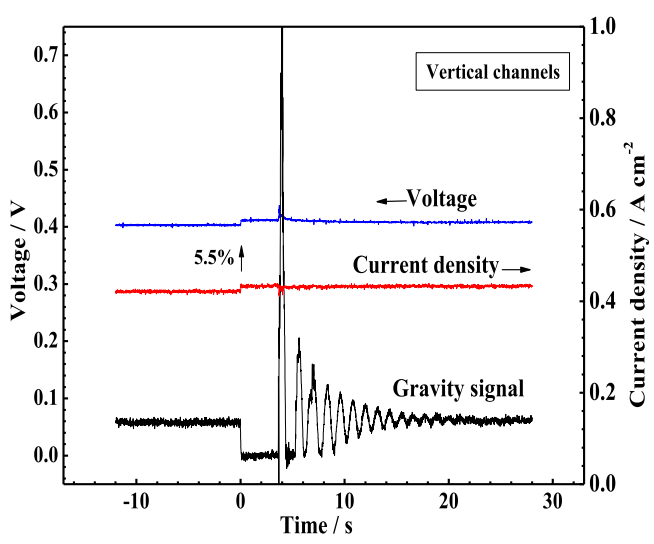

(a) Performance behaviors with varying gravity environment of the PEMFC with vertical channels

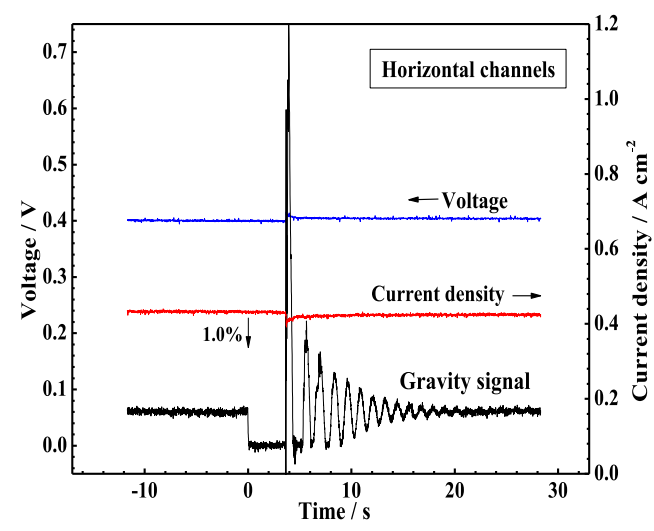

(b) Performance behaviors with varying gravity environment of the PEMFC with horizontal channels

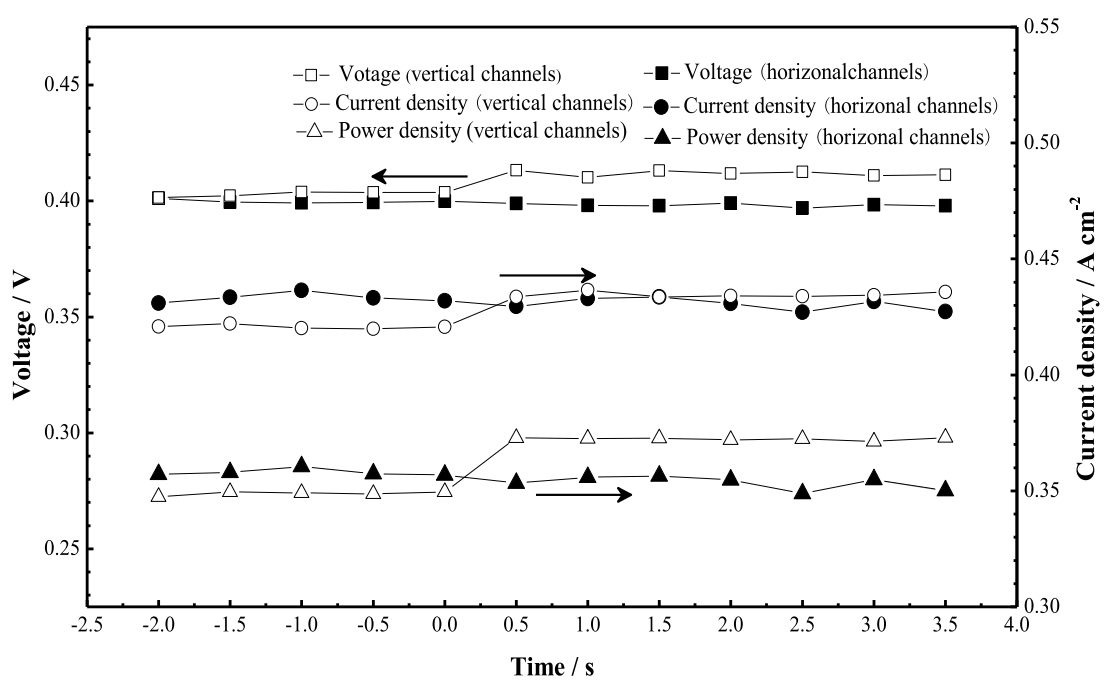

(c) Performance comparison between the PEMFC with vertical channels and the PEMFC with horizontal

channels in the normal gravity environment and the short-term microgravity environment.

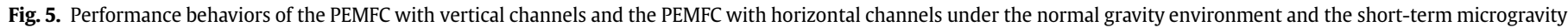
environment with high external load $\left(\mathrm{R}_{1}\right) . \mathrm{H}_{2}: 180 \mathrm{ml} \mathrm{min}^{-1}, \mathrm{O}_{2}: 60 \mathrm{ml} \mathrm{min}^{-1}, \mathrm{~T}_{\text {cell }}: 35^{\circ} \mathrm{C}, \mathrm{R}=\mathrm{R}_{1}$.

with the PEMFC with vertical channels in the normal gravity environment. What accounts for this is that: in the 3.6 s short-term microgravity environment, under high external circuit load, less liquid water accumulates in vertical channels and it is more beneficial to the electrochemical reaction compared with that in horizontal channels.

In addition, curves in Fig. 5 show that the voltage, current density, and power density of the PEMFC with vertical channels under high external load obviously increases and the current density increases by $5.5 \%$ when the PEMFC entered the $3.6 \mathrm{~s}$ shortterm microgravity environment from the normal gravity environment. However, the voltage, current density and power density of the PEMFC with horizontal channels exhibits slight change and the current density slightly decreases by $1.0 \%$ when it enters the $3.6 \mathrm{~s}$ short-term microgravity environment. What accounts for this is that: before the PEMFC enters the $3.6 \mathrm{~s}$ short-term microgravity environment, liquid water accumulates at the bottom of vertical channels, which results in higher polarization concentration and lower performance of the PMEFC. However, when the PEMFC with vertical channels enters the $3.6 \mathrm{~s}$ short-term microgravity environment, the water expulsion process is obvious in vertical channels and the accumulated water can be expelled out from the vertical channels, which causes an obvious change in the gas-liquid two-phase flow behaviors in the PEMFC with vertical channels and improve the performance of the PEMFC. While the horizontal channels are of benefit to the expulsion of the liquid water in both normal gravity environment and the $3.6 \mathrm{~s}$ short-term microgravity environment, which results in slight changes in the gas-liquid twophase flow behaviors and performance. Meanwhile when the PEMFC enters the $3.6 \mathrm{~s}$ short-term microgravity environment, the liquid water on the surface of the horizontal channels ascends and blocks the pores of the GDLs without the gravity effect, which accounts for the slight decrease in performance. The gas-liquid twophase flow behaviors are shown in the images in Fig. 6.

Fig. 6 shows the gas-liquid two-phase flow behaviors of the PEMFC with vertical channels and the PEMFC with horizontal channels in the normal gravity environment and the $3.6 \mathrm{~s}$ shortterm microgravity environment under high external circuit load $\left(R_{1}\right)$. Images are captured every $0.5 \mathrm{~s}$, and the PEMFC enters the short-term microgravity environment at 0.000 s. Fig. 6(b) shows 

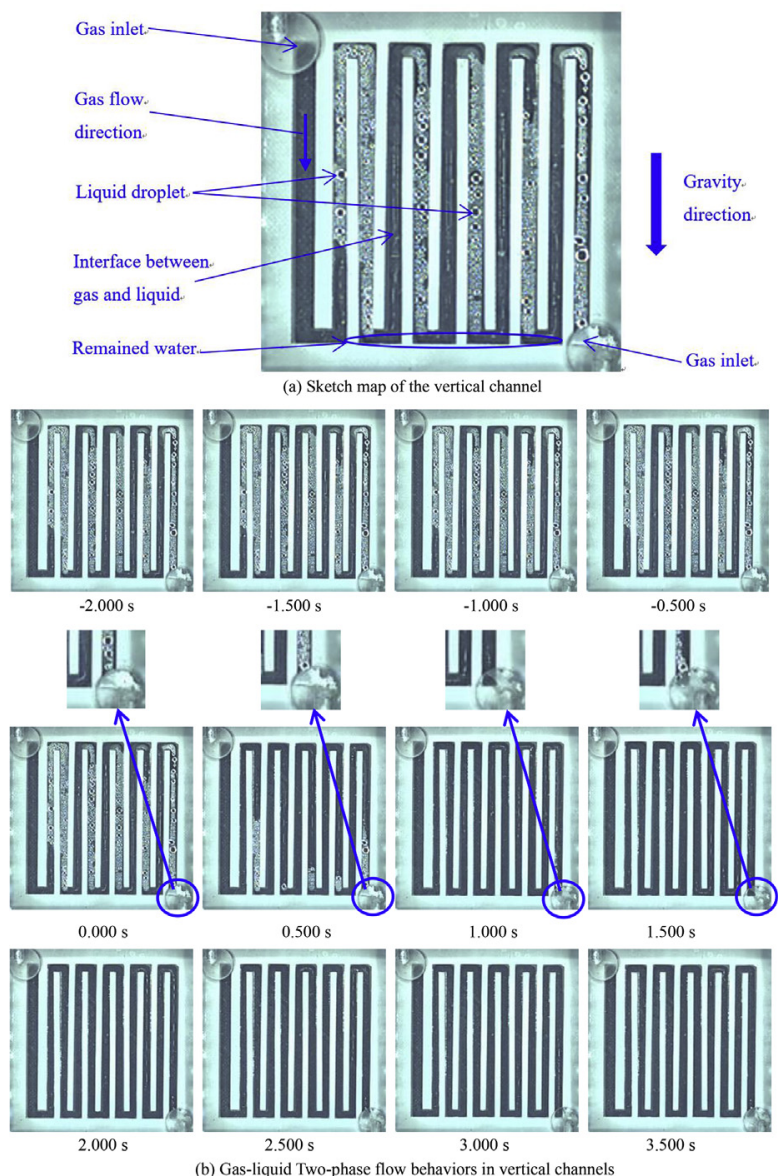

Gas flow direction

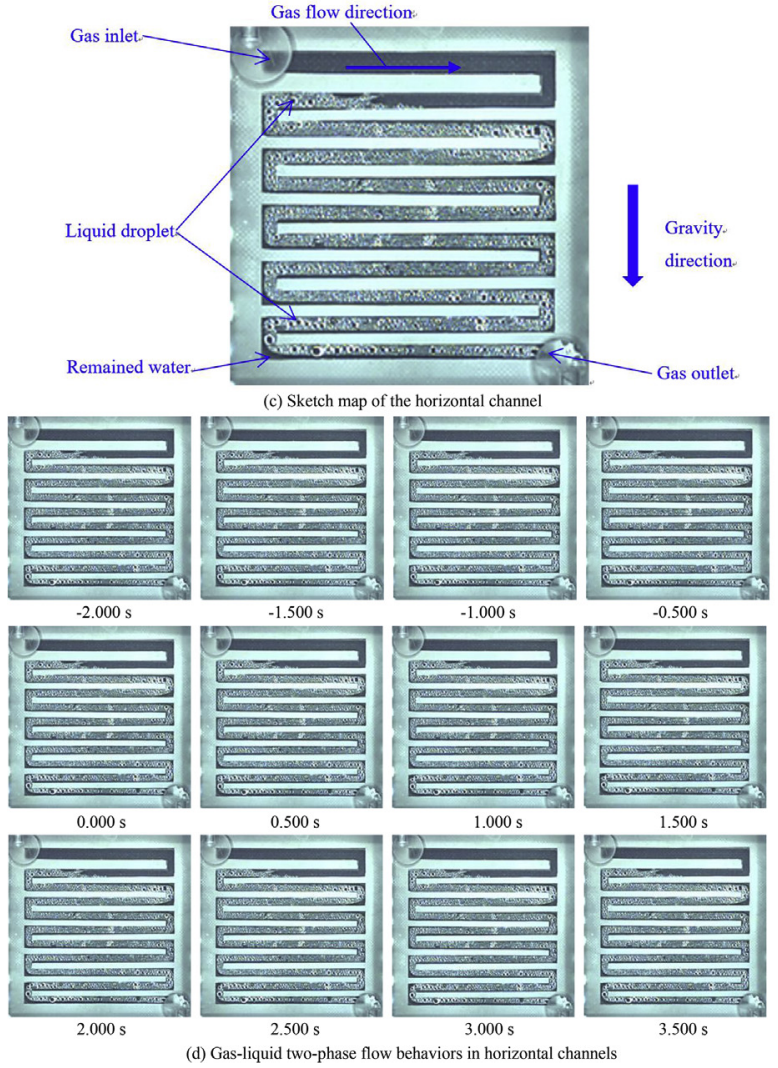

Fig. 6. Gas-liquid two-phase flow behaviors in cathode flow channels in the normal gravity environment and the short-term microgravity environment. $\mathrm{H}_{2}: 180 \mathrm{ml} \mathrm{min}^{-1}$,

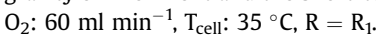

that the liquid droplets adhering to the surface of the internal wall can be observed before $0.000 \mathrm{~s}$, while they starts to disappear after $0.000 \mathrm{~s}$. Meanwhile during the working period in the normal gravity environment, liquid water of the electrochemical reaction accumulates at the bottom of channels under the action of gravity in vertical channels, while the accumulated water flows to the outlet when the PEMFC enters the $3.6 \mathrm{~s}$ short-term microgravity environment, as shown in Fig. 6(b). Liquid droplets adhering to the surface of the internal wall under the action of surface tension are clearly observed before the PEMFC enters the $3.6 \mathrm{~s}$ short-term microgravity environment. Liquid water transfers under the action of gas inertia and flows back to the bottom of ascending branches in channels under the effect of gravity, which induces the gas-liquid separation and flooded zone formation as the gas keep flowing to the outlet of channels. Formation of the flooded zone in channels results in the blockage of channels and the increase of the gas transfer resistance in channels. Meanwhile, the water-covered zone of the MEA prevents the reaction gas from entering the gas diffusion layers, thereby leading to the blockage of electrochemical reaction zone, which reduces the electrochemical reaction rate. However, when the PEMFC enters the short-term microgravity environment, because of the disappearance of gravity effect, liquid water accumulates at the bottom of uphill channel move with the flowing gas, which sweep the liquid droplets adhering to the surface of the internal wall away, and the liquid droplets move to the outlet of channels with the flowing gas. The interface between gas and liquid can be clearly observed and is not separated. The channels flooded by liquid water are exposed, and the gas transfer resistance in channels is reduced after the liquid water is expelled out of channels with the flowing gas. Thus, the concentration polarization is weakened, and the electrochemical reaction rate of the PEMFC is improved after the PEMFC enters the $3.6 \mathrm{~s}$ short-term microgravity environment, which causes the increase of the performance at $0.000 \mathrm{~s}$ (shown in Fig. 5).

The gas-liquid two-phase flow behaviors of the PEMFC with horizontal channels under high external load $\left(R_{1}\right)$ are shown in Fig. 6(d). Images in Fig. 6(d) show that the liquid droplets adhering to the surface of the internal wall can be observed before and after 0.000 s. During the normal gravity working period (before $0.000 \mathrm{~s}$ ), the liquid produced water can flow with the flowing gas and the liquid droplets adhering to the surface of the internal wall are not swept away by the flowing liquid water. Because most liquid water is swept away by the flowing gas at the first time when it appears on the surface of the GDL and little liquid water is accumulated on the surface of horizontal channels. When the PEMFC enters the $3.6 \mathrm{~s}$ short-term microgravity environment (after $0.000 \mathrm{~s}$ ), even the gravity effect disappears, the liquid droplets adhering to the surface of the internal wall are not swept away by the liquid water. What accounts for this is that: little accumulated water could flow with the flowing gas without the gravity effect and sweep the liquid droplets adhering to the surface of the internal wall away. The flow behaviors of the liquid water in channels are same in both normal gravity environment and the $3.6 \mathrm{~s}$ short-term microgravity environment and the produced liquid water do not touch the liquid droplets adhering to the surface of the internal wall of channels. Therefore, no obvious changes in the gas-liquid two-phase flow is observed after the PEMFC entered the 3.6 s short-term microgravity environment, which accounts for the obscure change in the concentration polarization and the performance of the PEMFC with horizontal channels (shown in Fig. 5).

\subsection{Low external circuit load operating regime}

Fig. 7 shows the performance of the PEMFC with vertical channels and the PEMFC with horizontal channels in the normal 


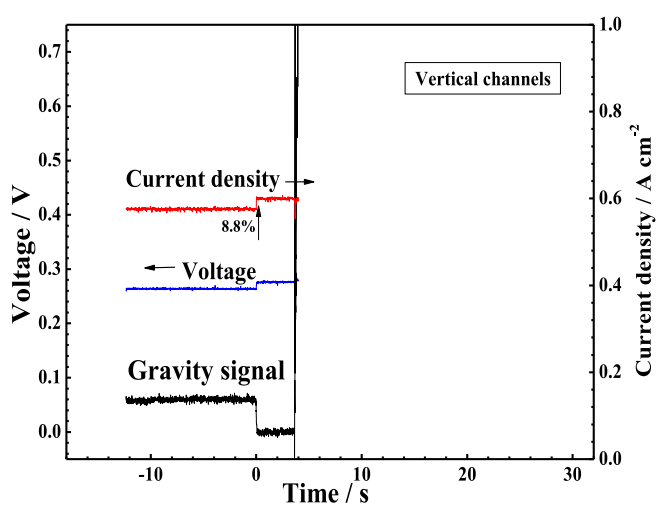

(a) Performance behaviors with varying gravity environment of the PEMFC with vertical channels

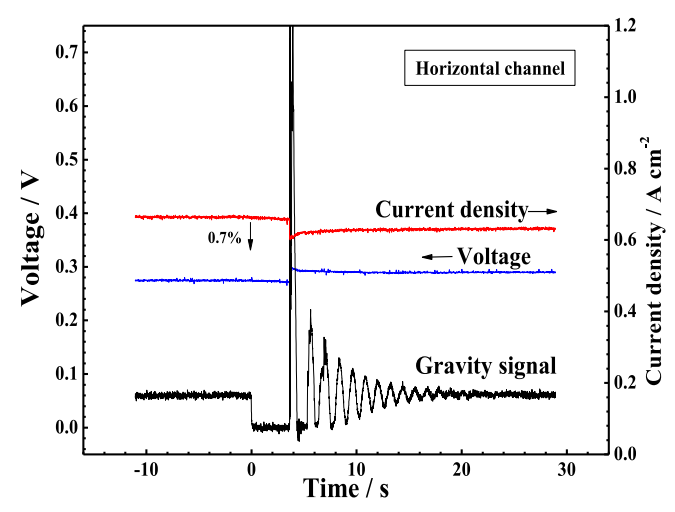

(b) Performance behaviors with varying gravity environment of the PEMFC with horizontal channels

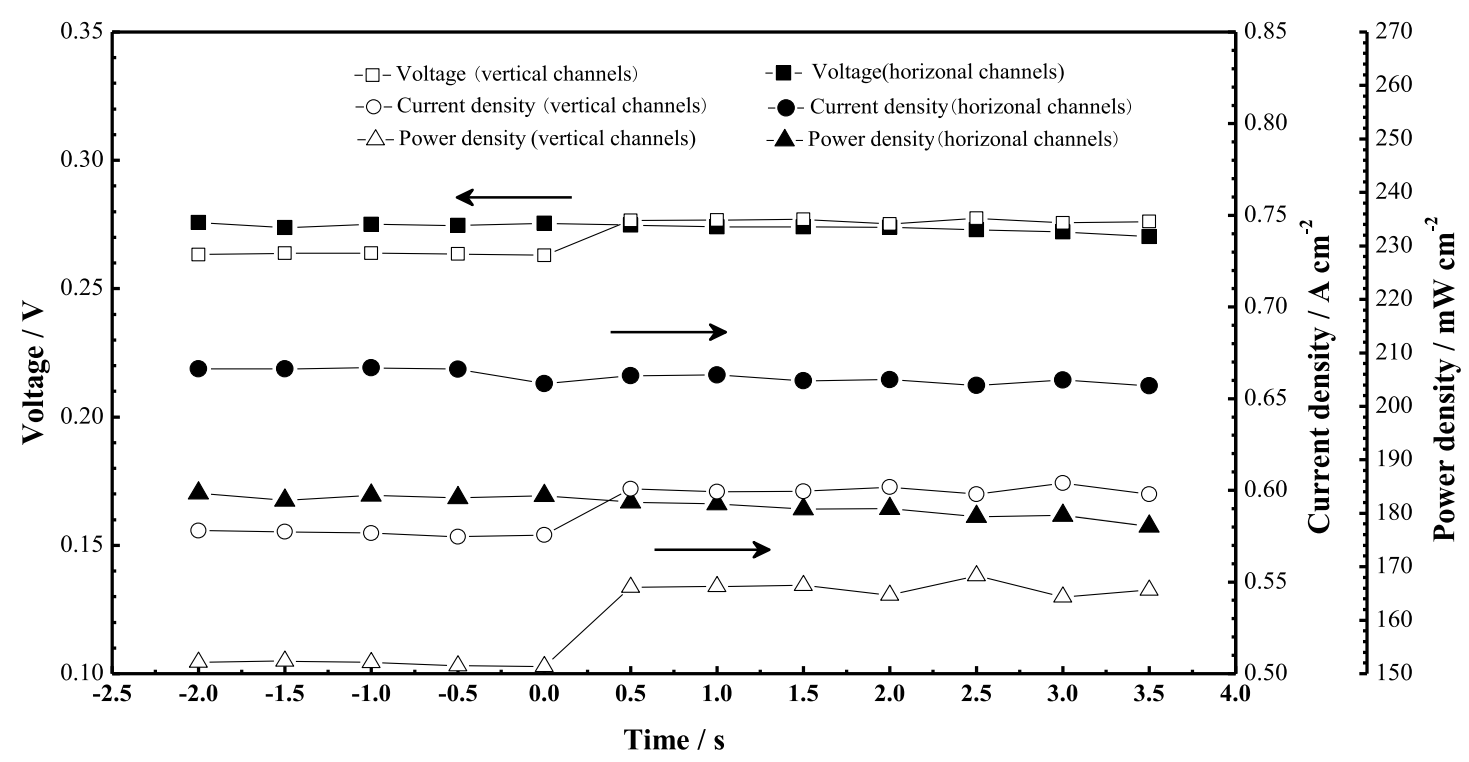

(c) Performance comparison between the PEMFC with vertical channels and the PEMFC with horizontal channels

in the normal gravity environment and the short-term microgravity environment

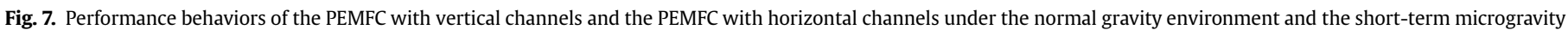
environment with low external load $\left(\mathrm{R}_{2}\right), \mathrm{H}_{2}: 180 \mathrm{ml} \mathrm{min}^{-1}, \mathrm{O}_{2}: 60 \mathrm{ml} \mathrm{min}^{-1}, \mathrm{~T}_{\text {cell }}: 35^{\circ} \mathrm{C}, \mathrm{R}=\mathrm{R}_{2}$.

gravity environment and the $3.6 \mathrm{~s}$ short-term microgravity environment under low external circuit load $\left(R=R_{2}\right)$. Fig. $7(a)$ and (b) show the performance changes of the PEMFCs with the gravity change. While Fig. 7(c) shows the performance comparison between the PEMFC with vertical channels and the PEMFC with horizontal channels in the normal gravity environment and the 3.6 s short-term microgravity environment. The fluctuation curve of alternating high gravity and microgravity in Fig. 7(a) is not collected because the data collection device is accidentally turned off, but this emergency do not affect the results of the present experimental work.

Curves in Fig. 7 show that the increase in voltage, current density and power density of the PEMFC with vertical channels appears and the current density increases by $8.8 \%$ when the PEMFC enters the $3.6 \mathrm{~s}$ short-term microgravity environment, whereas slight decrease are observed in the PEMFC with horizontal channels and the current density decreases by $0.7 \%$. This phenomenon is same with the case under high external circuit load and the reason for this is same as well. In addition, under low external circuit load, the
PEMFC with horizontal channels exhibits higher power density and higher current density compared with the PEMFC with vertical channels in both normal gravity environment and the $3.6 \mathrm{~s}$ shortterm microgravity environment. What accounts for this is that: the water in horizontal channels can be expelled out more easily compared with that in vertical channels in both normal gravity environment and the $3.6 \mathrm{~s}$ short-term microgravity environment. Meanwhile, water content in the PEMFC with horizontal channels is more beneficial to the electrochemical reaction in both normal gravity environment and the $3.6 \mathrm{~s}$ short-term microgravity environment compared with the PEMFC with vertical channels, which accounts for higher performance of the PEMFC with horizontal channels in both normal gravity environment and the $3.6 \mathrm{~s}$ shortterm microgravity environment.

Compared with Fig. 5, it can be observed that low external circuit load results in a more drastic change in performance compared with the case in the PEMFC with vertical channels under high external circuit load, where the current density suddenly increases by $8.8 \%$ (shown in Fig. 7 ) when the PEMFC entered the 3.6 s short- 


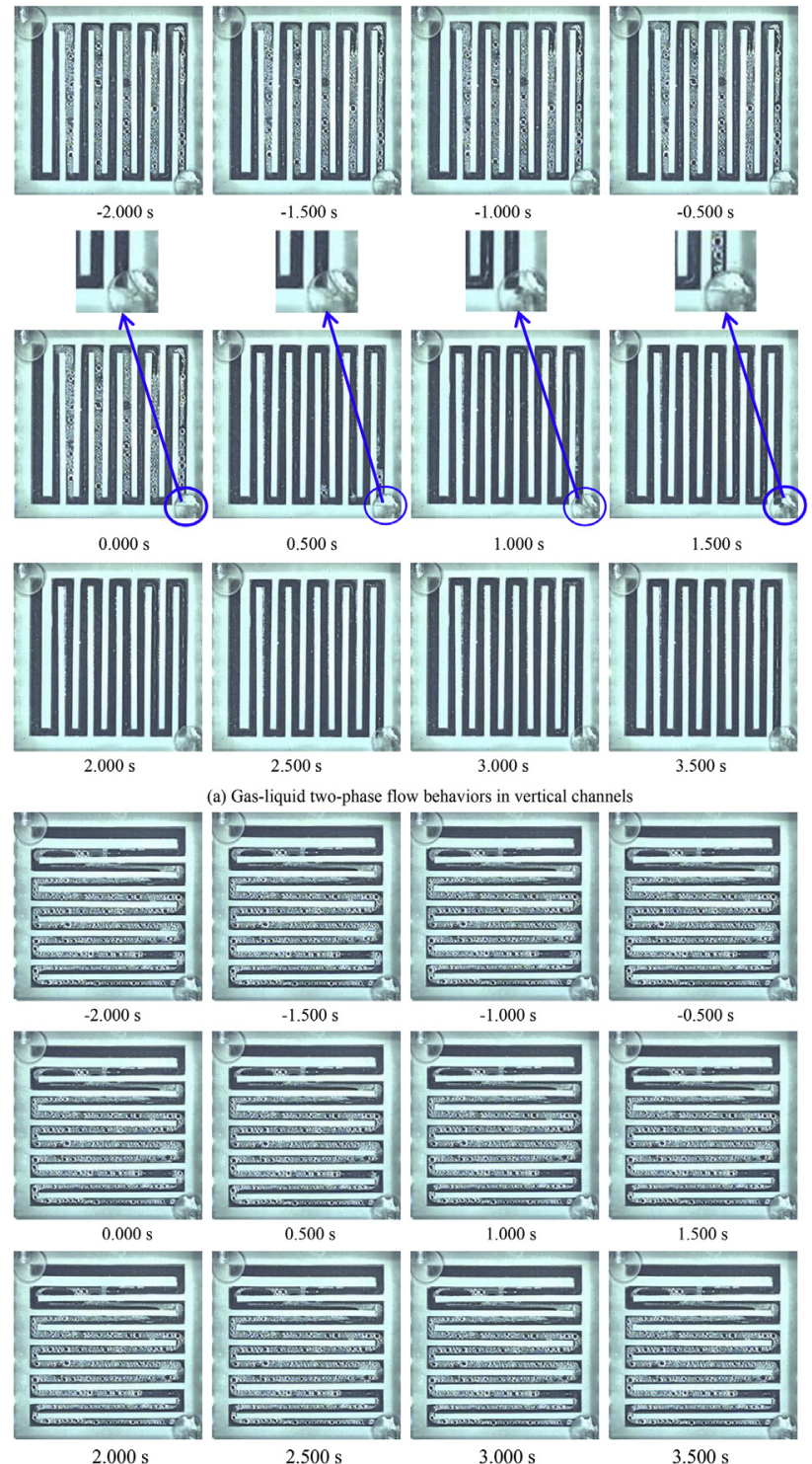

(b) Gas-liquid two-phase flow behaviors in horizontal channels
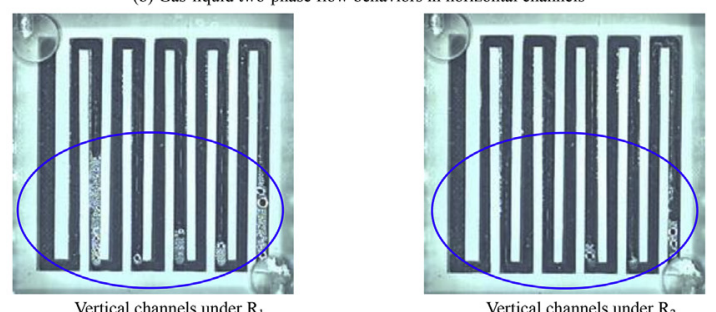

(c) Two-phase flow behaviors in vertical channels at $0.500 \mathrm{~s}$ after the drop capsule entered into the

microgravity environment

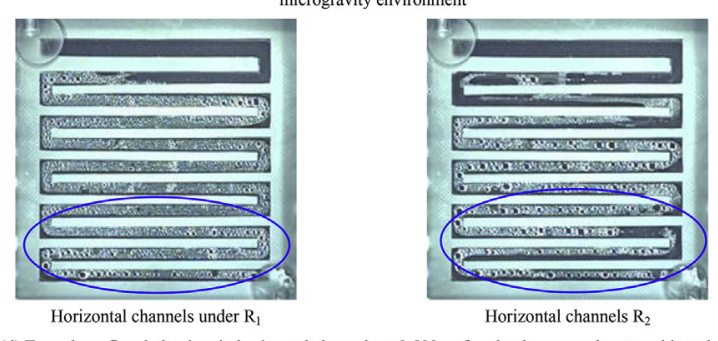

(d) Two-phase flow behaviors in horizontal channels at $0.500 \mathrm{~s}$ after the drop capsule entered into the

microgravity environment

Fig. 8. Gas-liquid two-phase flow behaviors in cathode flow channels in the normal gravity environment and the short-term microgravity environment $\mathrm{H}_{2}: 180 \mathrm{ml} \mathrm{min}^{-1}$,

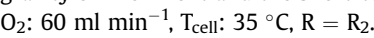

term microgravity. What accounts for this is that: under low external circuit load, higher amount of water is produced and accumulates at the bottom of the vertical channels because of the higher rate of electrochemical reaction. Meanwhile more accumulated water in the vertical channels is expelled out by the flowing gas because of the disappearance of the gravity effect when the PEMFC enters the $3.6 \mathrm{~s}$ short-term microgravity environment. This phenomenon causes a more drastic decrease in the concentration polarization, which improves the performance of the PEMFC more. The gas-liquid two-phase flow behaviors are shown in Fig. 8.

Fig. 8 shows the gas-liquid two-phase flow behaviors in the cathode flow channels of the PEMFC with vertical channels and the PEMFC with horizontal channels in the normal gravity environment and the $3.6 \mathrm{~s}$ short-term microgravity environment under low external circuit load $\left(R_{2}\right)$. Images in Fig. 8(a) show that the liquid droplets adhering to the surface of the internal wall of the PEMFC with vertical channels can be observed before $0.000 \mathrm{~s}$ in the normal gravity environment. However, the liquid droplets starts to disappear after $0.000 \mathrm{~s}$ when the PEMFC entered the $3.6 \mathrm{~s}$ short-term microgravity environment. However, the flowing gas and the flowing liquid water do not sweep the liquid droplets away from the internal wall (shown in Fig. 8(b)) of the PEMFC with horizontal channels. Those phenomena are same with the case under high external circuit load and the reasons accounts for them are same as well.

Compared with the case under high external circuit load, less liquid droplets can be observed on the surface of the internal wall of the PEMFC with vertical channels and the PEMFC with horizontal channels at $0.500 \mathrm{~s}(0.5 \mathrm{~s}$ after the drop capsule entered microgravity) under low external circuit load (shown in Fig. 8(c) and (d)). This phenomenon meant that the liquid droplets are swept away from the surface of the internal channel wall of the PEMFC with vertical channels and the PEMFC with horizontal channels in a higher rate. This is because that more liquid water accumulates at the bottom of the vertical channels and the surface of the horizontal channels under low external circuit load and the moving water with the flowing gas without the gravity effect can remove the liquid droplets adhering to the internal surface in a higher rate. Therefore, under low external circuit load, the gas-liquid two-phase flow behaviors, which heavily affects the polarization concentration, causes more obvious performance changes of the PEMFC with vertical channels and the PEMFC with horizontal channels in the $3.6 \mathrm{~s}$ short-term microgravity compared with the case under high external circuit load.

\section{Conclusions}

A PEMFC with vertical channels and A PEMFC with horizontal channels with transparent windows are designed in the present work to investigate their characteristics of performance and gasliquid two-phase flow behaviors of inside channels in a normal gravity environment and a 3.6 s short-term microgravity environment. Performance curves and images of gas-liquid two-phase flow behaviors in a normal gravity environment and a short-term microgravity environment are obtained through experiments.

1. In vertical channels, the liquid water accumulates at the bottom of the vertical flow channels in the normal gravity environment. When the PEMFC enters the short-term microgravity environment, the accumulated water is expelled out of the flow channels, which causes a sharply increase in the performance.

2. In horizontal channels, most liquid water is swept away at the first time when it appears at the surface of the GDL and little water accumulated at the surface of the horizontal flow channels in the normal gravity environment. When the PEMFC enters the shortterm microgravity environment, the little accumulated water 
ascends to the surface of the GDL and is expelled out of the flow channels, which accounts for a slight decrease in the performance.

3. Under high external circuit load, and the performance of the PEMFC with vertical channels is better than the performance of the PEMFC with horizontal channels in the short-term microgravity environment, whereas the performance of the PEMFC with horizontal channels is better than the performance of the PEMFC with vertical channels in the normal gravity environment. However, under low external circuit load, the performance of the PEMFC with horizontal channels is better than the performance of the PEMFC with vertical channels in both normal gravity environment and microgravity environment.

\section{Acknowledgements}

The Authors wish to show their sincere appreciation for the financial support from the National Natural Science Foundation of China (Grant No. 51476003). The authors gratefully thank Mr. Xiao Hui WU, Mr. Shi Xin WAN, and Mr. Ming Gang WEI for the kind help and discussion, and they also thank Mr. Hao CHEN for the typesetting.

\section{References}

[1] Y. Sone, M. Ueno, H. Naito, S. Kuwajima, One kilowatt-class fuel cell system for the aerospace applications in a micro-gravitational and closed environment, J. Power Sources 157 (2) (2006) 886-892.

[2] M. Warshay, P. Prokopius, M. Le, G. Voecks, The NASA fuel cell upgrade program for the space shuttle orbiter, Energy Convers. Eng. Conf. 1 (1997) $228-231$.

[3] N. Lior, Power from space, Energy Convers. Manag. 42 (15) (2009) 1769-1805.

[4] K.A. Burke, Fuel Cell for Space Science Application, NASA/TM-2003-212730, NASA: NASA/TM-2005-213381, NASA: NASA Center for Aerospace Information, 2005, pp. 1-19.

[5] T.C. Yau, M. Cimenti, X.T. Bi, J. Stumper, Effects of cathode gas diffusion layer design on polymer electrolyte membrane fuel cell water management and performance, J. Power Sources 196 (22) (2011) 9437-9444.

[6] Z.J. Lu, C. Rath, G.S. Zhang, S.G. Kandlikar, Water management studies in PEM fuel cells, part IV: effects of channel surface wettability, geometry and orientation on the two-phase flow in parallel gas channels, Int. J. Hydrogen Energy 36 (16) (2011) 9864-9875.

[7] X. Wang, B. Zhou, Liquid water flooding process in proton exchange membrane fuel cell cathode with straight parallel channels and porous layer, J. Power Sources 196 (4) (2011) 1776-1794.

[8] J.X. Liu, H. Guo, F. Ye, D.C. Qiu, C.F. Ma, Interfacial phenomena and heat transfer in proton exchange membrane fuel cells, Interfacial Phenom. Heat Transf. 3 (3) (2015) 259-301.

[9] J.P. Owejan, T.A. Trabold, D.L. Jacobson, M. Arif, S.G. Kandlikar, Effects of flow field and diffusion layer properties on water accumulation in a PEM fuel cell, Int. J. Heat Mass Transf. 32 (17) (2007) 4489-4502.

[10] A. Turhan, K. Heller, J.S. Brenizer, M.M. Mench, Quantification of liquid water accumulation and distribution in a polymer electrolyte fuel cell using neutron imaging, J. Power Sources 160 (2) (2006) 1195-1203.

[11] X. Li, I. Sabir, J. Park, A flow channel design procedure for PEM fuel cells with effective water removal, J. Power Sources 163 (2) (2007) 933-942.

[12] S. Litster, D. Sinton, N. Djilali, Ex-situ visualization of liquid water transport in PEM fuel cell gas diffusion layers, J. Power Sources 154 (1) (2006) 95-105.

[13] A. Bazylak, D. Sinton, Z.S. Liu, N. Djilali, Effect on compression on liquid water transport and microstructure of PEMFC gas diffusion layers, J. Power Sources 163 (2) (2007) 784-792.

[14] J. Lee, J. Hinebaugh, A. Bazylak, Synchrotron X-ray radiographic investigations of liquid water transport behaviors in a PEMFC with MPL-coated GDLs, J. Power Sources 227 (2013) 123-130.

[15] T. Sasabe, S. Sushima, S. Hirai, In-situ visualization of liquid water in an operating PEMFC by soft X-ray radiography, Int. J. Hydrogen Energy 35 (20) (2009) 11119-11128.

[16] P. Deevahxay, T. Sasabe, S. Tsushima, S. Hirai, Investigation of water accumulation and discharge behaviors with variation of current density in PEMFC by high-resolution soft X-ray radiography, Int. J. Hydrogen Energy 36 (17) (2011) 10901-10907.

[17] X.F. Zhang, T. Zhang, Review on water content measurement technology for PEM fuel cell, Chin. J. Sci. Instrum. 33 (9) (2012) 2151-2160.

[18] H. Guo, C.F. Ma, M.H. Wang, J. Yu, X. Liu, F. Ye, C.Y. Wang, Heat and mass transfer and two-phase flow in hydrogen proton exchange membrane fuel cells and direct methanol fuel cells, Asme International Conference on Fuel Cell Science, Eng. Technol. (2003) 471-476.
[19] X.G. Yang, F.Y. Zhang, A.L. Lubawy, C.Y. Wang, Visualization of liquid water transport in a PEFC, Electrochem. Solid State Lett. 7 (11) (2004) A408-A411.

[20] F.Y. Zhang, X.G. Yang, C.Y. Wang, Liquid water removal from a polymer electrolyte fuel cell, J. Electrochem. Soc. 153 (2) (2006) A225-A232.

[21] J.X. Chen, An effective discharge method for condensed water inside the GDL using pressure gradient of a PEM fuel cell, Int. J. Heat Mass Transf. 85 (2015) 703-710.

[22] F.B. Weng, A. Su, C.Y. Hsu, The study of the effect of gas stoichiometric flow rate on the channel flooding and performance in a transparent fuel cell, Int. J. Hydrogen Energy 32 (6) (2007) 666-676.

[23] F.B. Weng, A. Su, C.Y. Hsu, C.Y. Lee, Study of water-flooding behaviour in cathode channel of a transparent proton-exchange membrane fuel cell, J. Power Sources 157 (2) (2006) 674-680.

[24] K. Tüber, D. Pócza, Visualization of water buildup in the cathode of a transparent PEM fuel cell, J. Power Sources 124 (2) (2003) 403-414.

[25] D. Spernjak, A.K. Prasad, S.G. Advani, Experimental investigation of liquid water formation and transport in a transparent single-serpentine PEM fuel cell, J. Power Sources 170 (2) (2007) 334-344.

[26] M.R. Hu, G.Y. Cao, Research on the performance differences between a standard PEMFC single cell and transparent PEMFC single cells using optimized transparent flow field unit-Part I: design optimization of a transparent flow field unit, Int. J. Hydrogen Energy 41 (4) (2016) 2955-2966.

[27] M. Najjari, F. Khemili, S.B. Nasrallah, The effects of the gravity on transient responses and cathode flooding in a proton exchange membrane fuel cell, Int. J. Hydrogen Energy 38 (8) (2013) 3330-3337.

[28] S.Z. Chen, Y.H. Wu, Gravity effect on water discharged in PEM fuel cell cathode, Int. J. Hydrogen Energy 35 (7) (2010) 2888-2893.

[29] K. Nishida, R. Taniguchi, Y. Ishizaki, S. Tsushima, S. Hirai, Impacts of channe wettability and flow direction on liquid water transport in the serpentine flow field of a polymer electrolyte fuel cell, J. Power Sources 275 (1) (2015) $447-457$.

[30] J.C. Lee, T. Shay, S.K. Chang, Orientation-dependent performance of portable proton exchange membrane fuel cells, J. Fuel Cell Sci. Technol. 8 (3) (2011) 2279-2285.

[31] J.F. Zhao, H. Guo, F. Ye, S.X. Wan, M.G. Wei, F. Wu, C.P. Lv, C.F. Ma, Experimental study on two phase flow and power performance of DMFC utilizing the drop tower Beijing, Chin. J. Space Sci. 28 (1) (2008) 17-21.

[32] H. Guo, F. Wu, F. Ye, J.F. Zhao, S.X. Wan, C.P. Lv, C.F. Ma, Two-phase flow in anode flow field of a small direct methanol fuel cell in different gravities, Sci. China Ser E 52 (6) (2009) 1576-1582.

[33] F. Ye, F. Wu, J.F. Zhao, H. Guo, S.X. Wan, C.P. Lv, C.F. Ma, Experimental investigation of performance of a miniature direct methanol fuel cell in shortterm microgravity, Microgravity Sci. Technol. 22 (3) (2010) 347-352.

[34] H. Guo, J.F. Zhao, X. Liu, F. Ye, S.X. Wan, C.F. Ma, Experimental study of performance of proton exchange membrane fuel cell in short term microgravity condition, J. Eng. Thermophys. 30 (8) (2009) 1376-1378.

[35] H. Guo, X. Liu, J.F. Zhao, F. Ye, C.F. Ma, Experimental study of two-phase flow in a proton exchange membrane fuel cell in short-term microgravity condition, Appl. Energy 136 (31) (2014) 509-518.

[36] G.Y. Li, X.Q. Chen, Y.Y. Huang, Y. Chen, Study of the quasi-static motion of a droplet expelled from a pipe in microgravity, Acta Astronaut. 122 (2016) $35-41$.

[37] J.F. Zhao, Two-phase flow and pool boiling heat transfer in microgravity, Int. J. Multiph. Flow 36 (2) (2010) 135-143.

[38] J.F. Zhao, J.C. Xie, H. Lin, Y. Chen, Experimental study on two-phase gas-liquid flow patterns at the reduced gravity conditions, Sci. China 44 (5) (2001) $553-560$.

[39] J.F. Zhao, J.C. Xie, H. Lin, L.R. Hu, A.V. Ivanov, A.Y. Belyaev, Experimental studies on two-phase flow patterns aboard the mir space station, Int. J. Multiph. Flow 27 (11) (2001) 1931-1944.

[40] J.F. Zhao, W.R. Hu, Slug to annular flow transition of microgravity two-phase flow, Int. J. Multiph. Flow 26 (6) (2000) 1025-1027.

[41] M. Narcy, E.D. Malmazet, C. Colin, Flow boiling in tube under normal gravity and microgravity conditions, Int. J. Multiph. Flow 60 (2) (2014) 50-63.

[42] C. Konishi, H. Lee, I. Mudawar, M.M. Hasan, H.K. Nahra, N.R. Hall, J.D. Wagner R.L. May, J.R. Mackey, Flow boiling in microgravity: Part 1 - interfacial behaviors and experimental heat transfer results, Int. J. Heat Mass Transf. 81 (2015) 705-720.

[43] C. Konishi, H. Lee, I. Mudawar, M.M. Hasan, H.K. Nahra, N.R. Hall, J.D. Wagner, R.L. May, J.R. Mackey, Flow boiling in microgravity: Part 2 - critical heat flux interfacial behaviors, experimental data, and model, Int. J. Heat Mass Transf 81 (2015) 721-736.

[44] P.D. Jong, K.S. Gabriel, A preliminary study of two-phase annular flow at microgravity: experimental data of film thickness, Int. J. Multiph. Flow 29 (8) (2003) 1203-1220.

[45] M.R. Hu, G.Y. Cao, Research on the performance differences between a standard PEMFC single cell and transparent PEMFC single cells using optimized transparent flow field unitePart II: performance comparison and explanation, Int. J. hydrogen energy 54 (2016) 2967-2980.

[46] X.F. Hu, M. Chen, S.J. Liao, High performance fuel cell catalyst and 5kW PEMFC stack without humidification at room temperature and atmosphere, Electrochemistry 14 (4) (2008) 402-406. 